\title{
Chlamydia and lymphogranuloma venereum in Canada: 2003-2012 Summary Report
}

\author{
Totten $\mathrm{S}^{1, *}$, MacLean $\mathbf{R}^{1}$, Payne $\mathrm{E}^{1,}$ Severini, $\mathrm{A}^{2}$ \\ ${ }^{1}$ Centre for Communicable Diseases and Infection Control, Public Health Agency of Canada, Ottawa, ON \\ ${ }^{2}$ National Microbiology Laboratory, Public Health Agency of Canada, Winnipeg, MB \\ ${ }^{*}$ Correspondence: Stephanie.Totten@phac-aspc.gc.ca
}

\section{Abstract}

Background: Chlamydia continues to be the most commonly reported sexually transmitted infection in Canada. Lymphogranuloma venereum (LGV), caused by certain serovars of Chlamydia trachomatis, is becoming established in some populations in a number of Western countries.

Objective: To identify trends in reported cases of chlamydia and LGV in Canada from January 1, 2003 to December 31, 2012.

Methods: Notifiable disease data on chlamydia were submitted to the Public Health Agency of Canada by provincial and territorial epidemiological units and summarized at the national level by age and sex. Confirmatory testing for suspected LGV cases and serovar subtyping were performed by the National Microbiology Laboratory (NML). Where possible, provincial/territorial health authorities use a standardized national case report form to collect enhanced epidemiological data on each case and to submit the data to the Agency.

Results: Rates of reported cases of chlamydia increased by $57.6 \%$, from 189.6 to 298.7 per 100,000 between 2003 and 2012. The rate of reported cases of chlamydia among females $(383.5$ per 100,000) was almost twice as high as that among males (212.0 per 100,000), although the highest relative rate increase occurred among males. In both males and females, the rates of chlamydia were highest in those aged 20 to 24 years. From 2004 to 2012, 170 cases of LGV were reported to the Agency by provincial health authorities (including 104 confirmed and 66 probable cases). In 2012, case reports were received on 12 confirmed and probable cases, compared to 38 laboratory-positive cases confirmed by the NML.

Conclusion: In Canada, as in many countries, chlamydia rates have markedly increased over the last 10 years, in part due to improved diagnosis through nucleic acid amplification (NAAT) testing. Consistent with trends in Europe and other countries, LGV is emerging in Canada among men who have sex with men (MSM).

\section{Introduction}

\section{Chlamydia}

Chlamydia has been nationally notifiable since 1991. It is a genital infection caused by the bacterium Chlamydia trachomatis and is the most commonly reported sexually transmitted infection (STI) in Canada. Infections are often asymptomatic in both males and females. In the absence of screening, these infections remain undiagnosed and contribute to the spread of chlamydia in sexually active individuals (1). A common complication associated with untreated and recurring chlamydia in females is pelvic inflammatory disease, which can lead to chronic pelvic pain, ectopic pregnancy and infertility. In males, complications are rarer but include epididymo-orchitis and infertility. Untreated chlamydia in pregnant women can be transmitted to their newborns, causing neonatal conjunctivitis or pneumonia. As with other STIs, chlamydia increases infection with and transmission of the human immunodeficiency virus (HIV). It recruits target cells for HIV to the genital tract and increases the shedding of HIVinfected cells $(2,3)$. 
Between 1991 and 1997, the rate of reported cases of chlamydia decreased steadily among both males and females, after which rates began to rise (4).

\section{Lymphogranuloma venereum}

Lymphogranuloma venereum (LGV) is an STI caused by C. trachomatis serovars L1, L2 and L3. Infections caused by these serovars preferentially invade lymph tissue and tend to be more invasive than those caused by non-LGV chlamydia. Signs and symptoms include painful, ulcerative proctitis, with inguinal and/or femoral lymphadenopathy or buboes, accompanied by fever, myalgia and arthralgia.

Untreated LGV infection can result in severe complications including destruction of rectal and genital tissue. Although uncommon, in some cases, meningoencephalitis, hepatitis and death can also occur.

LGV is endemic in parts of Africa, Asia, South America and the Caribbean region and was relatively uncommon in Canada until 2003 (5). At that time, outbreaks of LGV began occurring among men who have sex with men in urban centres in Canada (6). Outbreaks among MSM have also been reported in European countries and the United States $(7,8,9,10)$. Recent data suggest that the infection has become endemic in the MSM population in some of these countries (11). In response to the emergence of LGV in Europe, Canada initiated enhanced surveillance of this STI in 2005 which included retrospective data from 2004.

The objective of this report is to summarize the trends in chlamydia and LGV rates in Canada between 2003 and 2012. It is based on the Report on Sexually Transmitted Infections in Canada: 2012 prepared by the Centre for Communicable Diseases and Infection Control of the Public Health Agency of Canada (PHAC) (available online) (12) and a supplementary statement on LGV (13).

\section{Methods}

\section{Data collection}

Data on laboratory-confirmed chlamydia cases were reported to the Canadian Notifiable Disease Surveillance System (CNDSS) by provincial and territorial health authorities according to the Agency's Case Definitions for Communicable Diseases under National Surveillance (14) (see box below). Data are submitted in a variety of formats (e.g., line-listed electronic, paper-based case reports, or aggregate data) and are verified and loaded into the CNDSS database by Agency personnel.

Confirmatory testing for suspected LGV cases is performed by the National Microbiology Laboratory (NML) by nucleic acid amplification testing (NAAT) and data on these cases are then shared with the Centre for Communicable Disease and Infection Control (CCDIC). Diagnosis of probable cases is based on serological testing alone and is done at provincial laboratories. Where possible, provincial/territorial health authorities use a standardized national case report form to collect enhanced epidemiological data on confirmed and probable cases and submit the data directly to CCDIC. At the current time, it is not possible to link case report forms on confirmed cases submitted to CCDIC with their corresponding NML data.

\section{Case definitions of chlamydia and lymphogranuloma venereum (LGV)}

Chlamydia: (14)

Laboratory evidence of infection in genitourinary and extra-genital specimens:

- Detection of Chlamydia trachomatis by culture,

OR

- Detection of C. trachomatis nucleic acid,

$\mathrm{OR}$

- Detection of C. trachomatis antigen.

Lymphogranuloma venereum (LGV): (13)

- Laboratory evidence of $C$. trachomatis L1, L2 or L3 by positive NAAT testing. 


\section{Data analysis}

Chlamydia data extracted from the CNDSS were analyzed by CCDIC staff. Rates were calculated by age group and sex using population estimates obtained from the Statistics Canada Demography Division. Rate change calculations were made on unrounded figures for greater precision.

Counts of LGV cases reported by the NML and by provincial/territorial health authorities are included separately, as there is currently no method of linking these two data sources. Confirmed cases reported by the NML may duplicate confirmed cases also reported by the provinces, but this degree of overlap is difficult to quantify.

Surveillance is considered to be within the mandate of F/P/T programs and does not constitute human research; therefore, no research ethics board approval was sought.

\section{Results}

\section{Chlamydia}

In 2012, 103,716 cases of chlamydia were reported, corresponding to a rate of 298.7 per 100,000 . The 2012 rate was a $57.6 \%$ increase from the rate of 189.6 per 100,000 in 2003 . Among males, rates increased by $74.8 \%$, from 121.3 to 212.0 per 100,000 ; among females, rates increased by $49.5 \%$, from 256.5 to 383.5 per 100,000 (Figure 1).

Figure 1: Overall and sex-specific rates of reported chlamydia cases, 2003 to 2012, Canada)

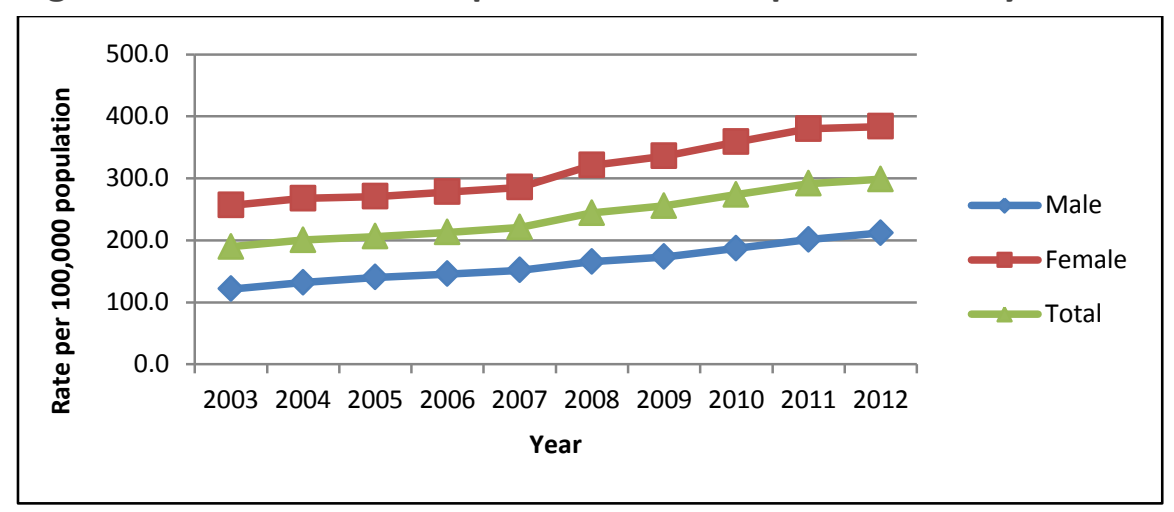

In 2012, rates were almost twice as high among females as compared to males and the majority (80.2\%) of reported chlamydia infections occurred in persons under 30 years (Figure 2). In 2012, the highest rates were in the age 20 to 24 age group, though rates in females were twice as high as in males of this age (2151.7 per 100,000 vs. 1073.9 per 100,000, respectively). Among older age groups, the gap between sexes was less pronounced and even reversed; in 2012, the rates of reported cases were higher among men than women in those aged 40 and older (Figure 2).

Between 2003 and 2012, rates of reported cases of chlamydia increased steadily among both males and females aged 10 and above. The highest relative rate increase occurred among those aged 10 to $14(167.0 \%)$ while the highest relative rate increase in females occurred among those aged 60 and over (266.8\%) (data not shown). 
Figure 2: Rates of reported chlamydia cases by sex and age group, 2012, Canada

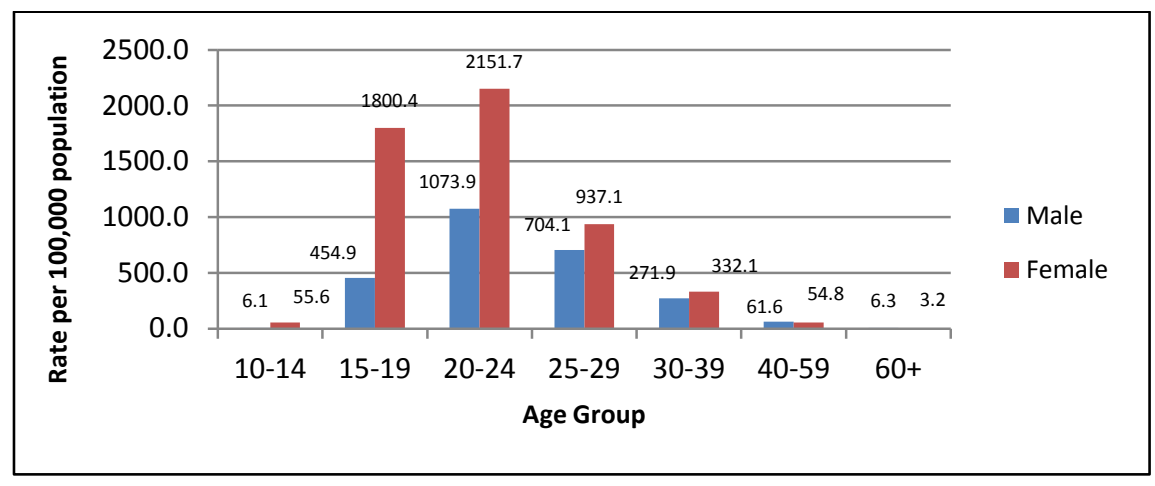

\section{Lymphogranuloma venereum}

As of December 2012, 170 cases were reported to the Agency by provincial health authorities (including 104 confirmed and 66 probable cases) (Table 1). All confirmed cases were male and predominantly MSM. In 2012 alone, there were eight confirmed and four probable cases reported by the provinces and territories, however, there were 38 laboratory-confirmed cases reported by the NML.

Table 1: Reported confirmed and probable cases of lymphogranuloma venereum, 2004-2012, Canada

\begin{tabular}{|r|r|r|r|}
\hline Year & $\begin{array}{r}\text { Confirmed } \\
\text { (NML) }\end{array}$ & $\begin{array}{r}\text { Confirmed } \\
\text { (case report form) }\end{array}$ & $\begin{array}{r}\text { Probable } \\
\text { (case report form) }\end{array}$ \\
\hline 2004 & 1 & 3 & 7 \\
\hline 2005 & 37 & 36 & 21 \\
\hline 2006 & N/A & 26 & 16 \\
\hline 2007 & N/A & 1 & 7 \\
\hline 2008 & N/A & 1 & 4 \\
\hline 2009 & N/A & 9 & 0 \\
\hline 2010 & 18 & 9 & 2 \\
\hline 2011 & 34 & 11 & 5 \\
\hline 2012 & 38 & 8 & 66 \\
\hline Total & 128 & 104 & 4 \\
\hline
\end{tabular}

\section{Discussion}

Increases in the rates of reported cases of chlamydia have been observed in Canada over the last decade. There are several factors that must be taken into account when considering these data.

The introduction of more sensitive nucleic acid amplification testing (NAAT) in the mid-1990s undoubtedly led to an increase in the number of chlamydia cases detected. NAAT allows urine specimens to be used rather than swabs, which are easier to collect and more acceptable to patients. As a result, the number of people, particularly males, who go for testing has likely increased as well. More effective screening and contact tracing may have a similar effect $(15,16)$. A recent estimation of chlamydia disease burden in Canada found that observed increases in chlamydia prevalence could be explained by effective case finding and expansion of screening programs (17).

Over time, the rate of reported cases of chlamydia has consistently been approximately twice as high in females as in males; however, this disparity is much more pronounced in younger age groups. Younger women are biologically more susceptible to chlamydial infection $(18,19)$. In addition, women are more likely to be screened for STIs $(20,21)$. 
Trends in LGV infection are difficult to interpret due to gaps in available data, but there is evidence that it is becoming endemic among MSM in Canada. Early surveillance efforts were intensive, followed by a period of time (2007-2009) when few cases were reported. The more recent increase in cases beginning in 2010 and continuing into 2012 likely reflects improved case finding and reporting (22).

National guidelines for the prevention and management of chlamydial infections are available $(2,23)$ and treatment guidelines for LGV have recently been updated (13).

\section{Acknowledgements}

The full report was prepared by the Centre for Communicable Diseases and Infection Control, Infectious Disease Prevention and Control Branch, Public Health Agency of Canada. Its publication would not have been possible without the collaboration of all provinces and territories, whose continuous contribution to national STI surveillance is greatly appreciated. The authors also acknowledge the contributions and expertise of the Sexually Transmitted and Blood-Borne Infections Surveillance Network.

\section{Conflict of interest}

None

\section{Funding}

This work was supported by the Public Health Agency of Canada.

\section{References}

(1) Stamm WE. Chlamydia trachomatis infections of the adult. In: Holmes KK, Sparling PF, Mardh P, Lemon SM, Stamm WE, Piot P, et al., editors. Sexually transmitted diseases. 3rd ed. New York: McGraw-Hill; 1999. p. 407-422.

(2) Expert Working Group for the Canadian Guidelines on Sexually Transmitted Infections. Chlamydial Infections. In: Wong T, Latham-Carmanico C, editors. Canadian guidelines on sexually transmitted infections. 2010 ed. Ottawa: Public Health Agency of Canada; 2010.

(3) Fleming DT, Wasserheit JN. From epidemiological synergy to public health policy and practice: The contribution of other sexually transmitted diseases to sexual transmission of HIV infection. Sex Transm Infect. 1999 Feb;75(1):3-17.

(4) Public Health Agency of Canada. Report on sexually transmitted infections in Canada: 2011. Centre for Communicable Diseases and Infection Control, Infectious Disease Prevention and Control Branch, Public Health Agency of Canada; 2014. http://publications.gc.ca/site/eng/469949/publication.html.

(5) Expert Working Group for the Canadian Guidelines on Sexually Transmitted Infections. Lymphogranuloma venereum (LGV). In: Wong T, Latham-Carmanico C, editors. Canadian Guidelines on Sexually Transmitted Infections. 2010 ed. Ottawa: Public Health Agency of Canada; 2010.

(6) Kropp RY, Wong T, Canadian LGV Working Group. Emergence of lymphogranuloma venereum in Canada. CMAJ. 2005 Jun 21;172(13):1674-1676.

(7) Bremer V, Meyer T, Marcus U, Hamouda O. Lymphogranuloma venereum emerging in men who have sex with men in Germany. Euro Surveill. 2006 Sep;11(9):152-154.

(8) Koedijk FD, de Boer IM, de Vries HJ, Thiesbrummel HF, van der Sande MA. An ongoing outbreak of lymphogranuloma venereum in the Netherlands, 2006-2007. Euro Surveill. 2007 Apr 19;12(4):E070419.2.

(9) Jebbari H, Alexander S, Ward H, Evans B, Solomou M, Thornton A, et al. Update on lymphogranuloma venereum in the United Kingdom. Sex Transm Infect. 2007 Jul;83(4):324-326.

(10) HIV, STD and Hepatitis Prevention Branch, Public Health Services, Health and Human Services Agency, San Diego County. Lymphogranuloma venereum (LGV) update. 2005.

(11) Savage EJ, van de Laar MJ, Gallay A, van der Sande M, Hamouda O, Sasse A, et al. Lymphogranuloma venereum in Europe, 2003-2008. Euro Surveill. 2009 Dec 3;14(48):19428.

(12) Public Health Agency of Canada. Report on sexually transmitted infections in Canada: 2012. Centre for Communicable Diseases and Infection Control, Infectious Disease Prevention and Control Branch, Public Health Agency of Canada; 2015. 
(13) Public Health Agency of Canada. A supplementary statement concerning the laboratory diagnosis of LGV. Canadian guidelines on sexually transmitted tnfections. http://www.phac-aspc.gc.ca/std-mts/sti-its/cgsti-Idcits/supp-lgv-eng.php

(14) Public Health Agency of Canada. Case definitions for communicable diseases under national surveillance Can Comm Dis Report. 2009; 35;S-2.

(15) McKay A, Barrett M. Rising reported rates of chlamydia among young women in Canada: What do they tell us about trends in the actual prevalence of the infection? Can J Hum Sex. 2008;17(1-2):61-69.

(16) Rekart ML, Brunham RC. Epidemiology of chlamydial infection: Are we losing ground? Sex Transm Infect. 2008 Apr;84(2):87-91.

(17) Tuite AR, Jayaraman GC, Allen VG, Fisman DN. Estimation of the burden of disease and costs of genital Chlamydia trachomatis infection in Canada. Sex Transm Dis. 2012 Apr;39(4):260-267.

(18) Lee V, Tobin JM, Foley E. Relationship of cervical ectopy to chlamydia infection in young women. J Fam Plann Reprod Health Care. 2006 Apr;32(2):104-106.

(19) Junior JE, Giraldo PC, Goncalves AK, do Amaral RL, Linhares IM. Uterine cervical ectopy during reproductive age: Cytological and microbiological findings. Diagn Cytopathol. 2014 May;42(5):401-404.

(20) Riera-Montes M, Velicko I. The chlamydia surveillance system in Sweden delivers relevant and accurate data: Results from the system evaluation, 1997-2008. Euro Surveill. 2011 Jul 7;16(27):19907.

(21) Machalek K, Hanley B, Kajiwara J, Pasquali P, Stannard C. Chlamydia screening practices among physicians and community nurses in Yukon, Canada. Int J Circumpolar Health. 2013;72(22447).

(22) Linedegger M, Salway Hottes T, Gilbert M, Lester R, Imperial M, Hoang L. Lymphogranuloma venereum in British Columbia: 2004 to 2011. Epidemiology and Surveillance, Clinical Prevention Services 2012.

(23) Public Health Agency of Canada. Canadian guidelines for sexual health education. Ottawa: Public Health Agency of Canada; 2008. 